\title{
Biodistribution and Molecular Studies on Orally Administered Nanoparticle-AON Complexes Encapsulated with Alginate Aiming at Inducing Dystrophin Rescue in $m \boldsymbol{d x}$ Mice
}

\author{
Maria Sofia Falzarano, ${ }^{1}$ Chiara Passarelli, ${ }^{2}$ Elena Bassi, ${ }^{1}$ Marina Fabris, ${ }^{1}$ \\ Daniela Perrone, ${ }^{3}$ Patrizia Sabatelli, ${ }^{4}$ Nadir M. Maraldi, ${ }^{4}$ Silvia Donà, ${ }^{5}$ \\ Rita Selvatici, ${ }^{1}$ Paolo Bonaldo, ${ }^{5}$ Katia Sparnacci, ${ }^{6}$ Michele Laus, ${ }^{6}$ Paola Braghetta, ${ }^{5}$ \\ Paola Rimessi, ${ }^{1}$ and Alessandra Ferlini ${ }^{1,7}$ \\ ${ }^{1}$ Department of Medical Sciences, University of Ferrara, 44121 Ferrara, Italy \\ ${ }^{2}$ Unit of Molecular Medicine for Neuromuscular and Neurodegenerative Diseases, Bambino Gesù Children's Hospital, \\ IRCCS, 00146 Rome, Italy \\ ${ }^{3}$ Department of Biology and Evolution, University of Ferrara, 44121 Ferrara, Italy \\ ${ }^{4}$ IGM-CNR, Unit of Bologna c/o IOR, 40136 Bologna, Italy \\ ${ }^{5}$ Department of Biomedical Sciences, University of Padua, 35121 Padua, Italy \\ ${ }^{6}$ Department of Environmental and Life Sciences INSTM, University of Eastern Piedmont, 15121 Alessandria, Italy \\ ${ }^{7}$ Department of Medical Sciences, Section of Medical Genetics, University of Ferrara, via Fossato di Mortara 74, 44121 Ferrara, Italy
}

Correspondence should be addressed to Alessandra Ferlini; fla@unife.it

Received 1 July 2013; Revised 10 October 2013; Accepted 14 October 2013

Academic Editor: Akinori Nakamura

Copyright (C) 2013 Maria Sofia Falzarano et al. This is an open access article distributed under the Creative Commons Attribution License, which permits unrestricted use, distribution, and reproduction in any medium, provided the original work is properly cited.

We have previously demonstrated that intraperitoneal injections of $2^{\prime}$-O-methyl-phosphorothioate $\left(2^{\prime}\right.$ OMePS $)$ antisense oligoribonucleotides adsorbed onto a cationic core-shell nanoparticles (NPs), termed ZM2, provoke dystrophin restoration in the muscles of $m d x$ mice. The aim of the present work was to evaluate the oral route as an alternative way of administration for ZM2-antisense oligoribonucleotides complexes. The biodistribution and elimination of nanoparticles were evaluated after single and multiple oral doses of IR-dye conjugated nanoparticles. Labeled nanoparticles were tracked in vivo as well as in tissue cryosections, urines and feces by Odyssey infrared imaging system, and revealed a permanence in the intestine and abdominal lymph nodes for 72 hours to 7 days before being eliminated. We subsequently tested alginate-free and alginate-encapsulated ZM2-antisense oligoribonucleotides $(\mathrm{AON})$ complexes orally administered 2 and 3 times per week, respectively, in $m d x$ mice for a total of 12 weeks. Treatment with alginate ZM2-AON induced a slight dystrophin rescue in diaphragm and intestine smooth muscles, while no dystrophin was detected in alginate-free ZM2-AON treated mice. These data encourage further experiments on oral administration testing of NP and AON complexes, possibly translatable in oligoribonucleotides-mediated molecular therapies.

\section{Introduction}

The X-linked recessive Duchenne muscular dystrophy (DMD) affects 1 in 3500 newborn boys [1], and it is caused by the loss of dystrophin expression. The antisense mediated exon skipping approach represents a promising therapy for
DMD. It is based on the possibility to convert a severe phenotype (DMD) into a milder form (Becker muscular dystrophy) acting on dystrophin pre-mRNA $[2,3]$.

Two AON chemistries, $2^{\prime} \mathrm{OMePS}$ and phosphorodiamidate morpholino oligomer (PMO), have already been the subject of clinical trials in humans $[1,4-8]$. Phosphorothioate 


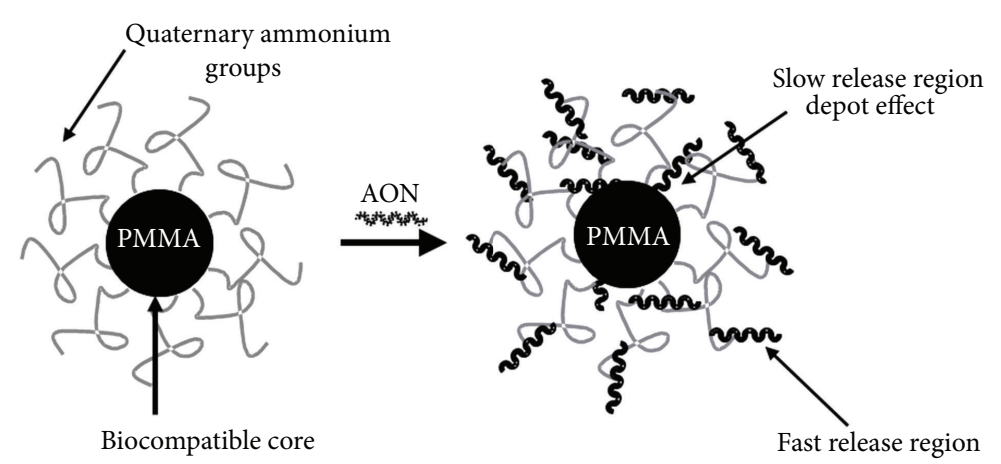

(a)

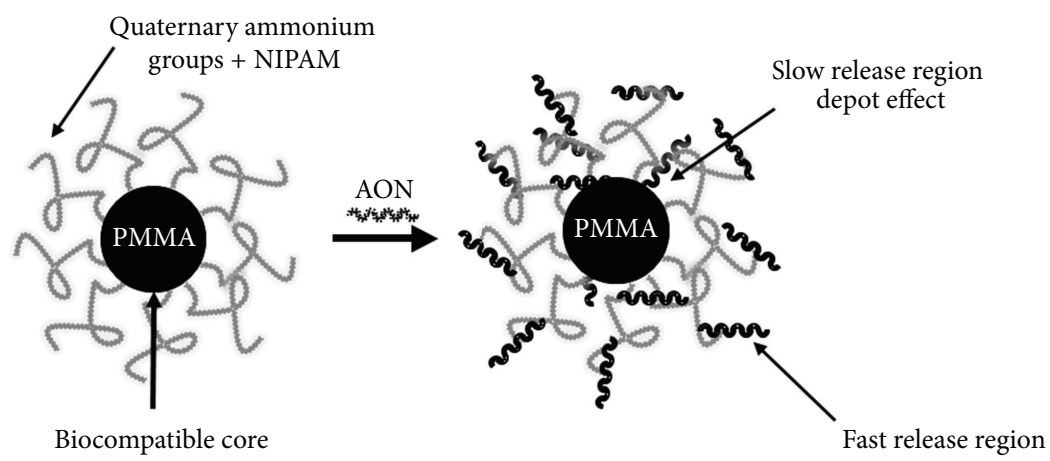

(b)

FIGURE 1: Nanoparticles characteristics. Representation of the interactions between antisense oligoribonucleotide (M23D AON) and quaternary ammonium groups on the surface of T1 (a) and ZM2 (b) nanoparticles.

(PS) oligonucleotides are the most widely studied AONs due to their stability to nucleolytic degradation and relative ease of synthesis. In PS oligonucleotides, the nonbridging oxygen is replaced with a sulfur atom in the oligonucleotide chain. This substitution confers sufficient stability in plasma, tissues, and cells to avoid degradation before binding to target RNA. PS-modified AONs are water-soluble and have high proteinbinding capacity, which prevents rapid renal excretion and facilitate uptake into tissues. PMO consists of the replacement of the phosphodiester bond by a phosphorodiamidate linkage with the ribose replaced by a morpholino moiety. PMOs are charge neutral, refractory to biological degradation and stable in serum and plasma [9-11].

In order to increase stability and half-life in biological fluids, thereby improving AON efficacy, different polymeric nanoparticles have been developed; their subcellular and submicron size allows them to penetrate deeply into tissues through the fine capillaries, crossing the fenestration present in the epithelial lining. We have previously demonstrated the effectiveness of polymethylmethacrylate (PMMA) T1 (Figure 1(a)) nanoparticles conjugated with AON to induce dystrophin restoration in body-wide muscles in the $m d x$ animal model. Although we obtained functional effect with oneeightieth of the normal AON dose regimen, the efficiency of this compound was relatively unsatisfactory in terms of size, AON loading capacity, and efficiency of treatment. Therefore, to obtain a more efficient compound, we designed and prepared a novel type of cationic core-shell NP (termed
ZM2), made up of a predominantly PMMA core and a random copolymer shell consisting of units derived from $\mathrm{N}$ isopropyl-acrylamide+ (NIPAM) and reactive methacrylatebearing cationic groups (Figure 1(b)). ZM2 nanoparticles were able to bind and deliver $2^{\prime}$ OMePS M23D AON in $m d x$ mice, inducing dystrophin restoration in the skeletal muscles, arrector pili smooth muscle, and heart after intraperitoneal (i.p.) treatment [12-15].

The $m d x$ mouse is the most widely used animal model for exon skipping experiments since it is a natural mutant with a stop mutation within exon 23 of the dystrophin gene. This causes a complete absence of dystrophin protein as well as a moderate muscle weakness. This stop mutation can be corrected using the exon skipping approach [16].

Indeed, treatment of $m d x$ mice with $2^{\prime}$ OMePS M23D AON induces the exclusion of the mutated exon 23 from mRNA resulting in an in-frame mRNA transcript and subsequent expression of a slightly shorter dystrophin protein in $m d x$ muscle $[12,17-19]$.

The objective of this work was to study the biodistribution, elimination, and efficacy of orally administered NPsAON in $m d x$ mice. The oral route is considered the most attractive for small molecules and macromolecular drug delivery, encompassing the advantages of easy administration, high patient compliance, and cost-effectiveness [20, 21]. The PS oligonucleotides molecules are poorly bioavailable when administered orally for their low mucosal permeability and poor transcytosis across the gut, due to both unfavorable 
TABLE 1: Nanoparticles characteristics.

\begin{tabular}{|c|c|c|c|c|c|c|}
\hline Sample & $\begin{array}{l}\text { Diameter }(\mathrm{SEM}) \mathrm{nm} \\
( \pm \text { standard error of } \\
\text { the mean })\end{array}$ & $\begin{array}{l}\text { Diameter }(\mathrm{PCS}) \mathrm{nm} \\
( \pm \text { polydispersity } \\
\text { index })\end{array}$ & $\begin{array}{c}\text { Quaternary } \\
\text { ammonium } \\
\text { groups } \mu \mathrm{mol} / \mathrm{g}\end{array}$ & $\begin{array}{c}\text { Primary } \\
\text { amino groups } \\
\mu \mathrm{mol} / \mathrm{g}\end{array}$ & NIPAM & Studies \\
\hline ZM2 & $137 \pm 9$ & $156 \pm 0.015$ & 202 & - & yes & $\begin{array}{l}\text { Functional analysis (dystrophin } \\
\text { rescue) with ZM2-AON and } \\
\text { ZM2-AON alginate }\end{array}$ \\
\hline ZM4 & $138 \pm 7$ & $143 \pm 0.012$ & 107 & 10.2 & yes & $\begin{array}{l}\text { Biodistribution and elimination } \\
\text { using dye NIR-797 }\end{array}$ \\
\hline
\end{tabular}

physicochemical properties (hydrophilicity, high molecular weight, high negative charge density) and to the depurination in the acidic gastric environment [22-25].

In order to protect molecules and facilitate drug permeation, different kinds of delivery systems are under study in order to inhibit hydrolysis, prolong intestinal retention, and thereby enhance drug bioavailability [26-30].

Alginate is one of the most common and suitable biopolymers. It is nontoxic, biodegradable, and employed to make acidic $\mathrm{pH}$-resistant hydrogel [31]. The most important property of alginates is their ability to form a reticulated structure in the presence of calcium ions, allowing the entrapment of molecules, making them good mucoadhesive agents [32, 33]. Alginate is a family of polysaccharides composed of $\alpha$-L-guluronic acid (G) and $\beta$-D-mannuronic acid residues $(\mathrm{M})$, arranged in homopolymeric blocks of each type and in heteropolymeric blocks [31].

Swelling of alginate is minimal in the stomach, while it increases moving toward the intestine, due to the $\mathrm{pH}$ increase [34]. In the present paper, we describe the biodistribution and elimination of ZM4 NPs conjugated with the dye NIR797 after single and multiple oral administrations, using the Near-Infrared fluorescent imaging System Odyssey (LI-COR Biosciences). The biodistribution studies indicate that NPs persist in the intestinal lumen for at least 72 hours after a single administration and are concentrated in the intestine and abdominal lymph nodes after multiple administrations before being completely eliminated at day 7 from the last treatment. Successively, we report on the results obtained using alginate as encapsulating agent for ZM2-AON complexes orally administered in $m d x$ mice. $m d x$ mice orally treated with alginate-free ZM2-M23D or alginate-coated ZM2-M23D revealed a slight rescue of dystrophin protein in the intestinal smooth muscles and a mild positivity in the diaphragm only when in the presence of alginate. The low rescue was associated with the absence of $\mathrm{AON}$ in tissues, as assayed by AON specific ELISA.

These results encourage further research into the oral administration route for antisense molecules.

\section{Results}

2.1. Biodistribution and Elimination of Nanoparticle Oral Treatment. To assess the biodistribution and elimination pathways, a novel NP sample was prepared, nominated ZM4. ZM4 features the same size, size distribution, and surface hydrophilicity as ZM2, but it also exposes at the surface, or in the swelled shell, primary amino groups. These groups are necessary to interact with the isothiocyanate groups of the NIR-797 fluorescent dye (Sigma-Aldrich), giving rise to ZM4-IR nanoparticles in which the dye is covalently incorporated into the shell (see Table 1 reporting the NPs characteristics). The in vivo biodistribution was evaluated, after a single or multiple oral administrations, employing the Odyssey Imaging System (Li-Cor Biosciences) that allows the specific distribution and clearance of the infrared dye-labeled nanoparticles to be tracked in live animals over time. See Table 2 for the schedule of treatments.

The Odyssey in vivo imaging time course of ZM4-IR after single or multiple administrations demonstrated the persistence of ZM4-IR in the intestinal lumen for at least 72 hours (Figure 2), and the absence of any NP accumulation. The positivity observed in the mouth (masseter) is due to residues of NP IR-dye formulations administered by gavage.

In the multiple administration schedule, ZM4-IR treated $m d x$ mice were killed following one week $(n=3)$ or one month $(n=3)$ from administration of the last dose. The analysis of cryosections from different organs shows that ZM4-IR NPs are still present in intestine and abdominal lymph nodes (Figure 3(a)) one week after treatment, while no NPs were detected in the organs of mice sacrificed 1 month after the last administration (Figure 3(b)). The positivity of the masseter muscle is probably due to local adsorption as a result of oral administration by gavage.

In the nanoparticles clearance studies, feces and urine samples were collected and analyzed with Odyssey. The feces of 3 untreated $m d x$ mice were used as negative controls. Neither the feces nor urine samples of the untreated mice showed any fluorescence, while the feces of treated mice showed an intense signal. NP clearance occurred almost exclusively through the feces and mainly in the first 48 hours after administration. In fact, by semiquantitative analysis it resulted that $90 \%$ of administered nanoparticles was detected in the feces samples collected during the first 12-36 hours after treatment, while the remaining $10 \%$ was gradually eliminated in the next few days, being completely removed after 7 days (data not shown).

\subsection{Dystrophin Restoration Studies: ZM2-M23D Complexes}

2.2.1. $m d x$ Mice Treatment. Table 3 summarizes the oral treatments and the sacrifice of mice analyzed in this work: $3 \mathrm{mdx}$ mice were administered for 12 weeks (2 doses/week) with ZM2-M23D complexes; $3 \mathrm{mdx}$ mice were treated for 12 weeks 


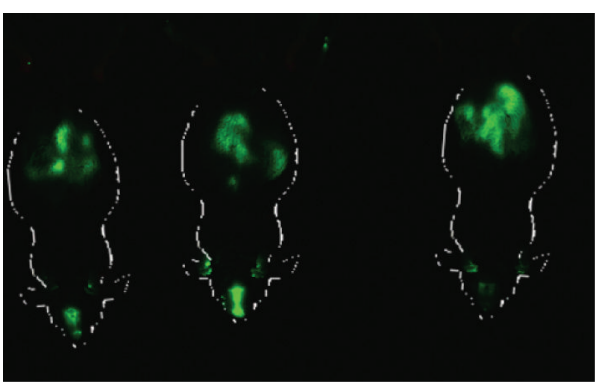

(a)

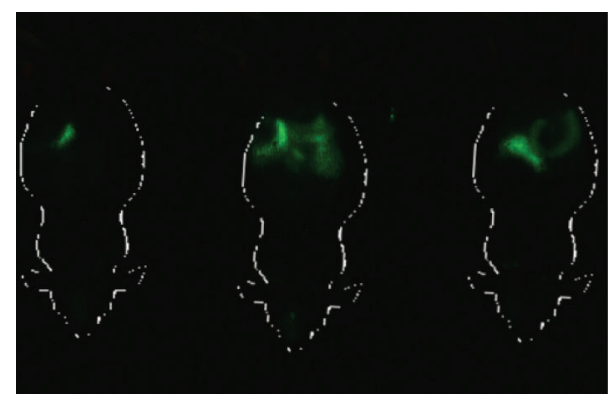

(c)

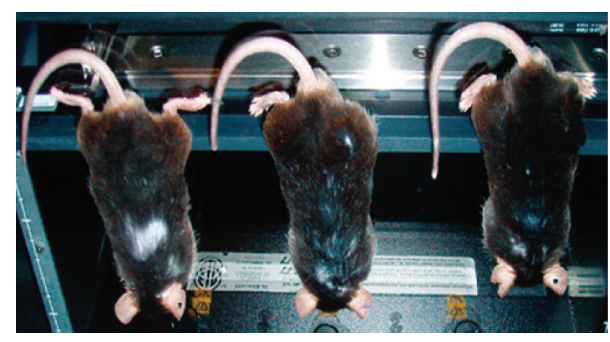

(e)

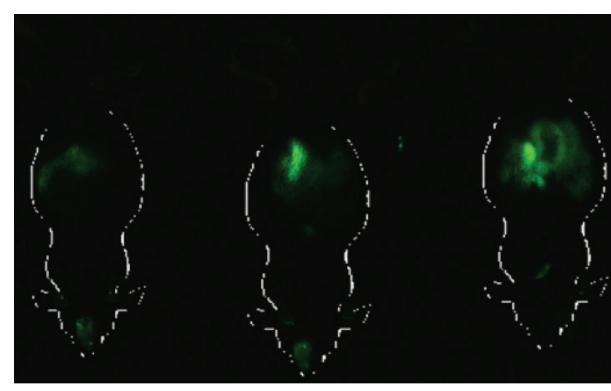

(b)

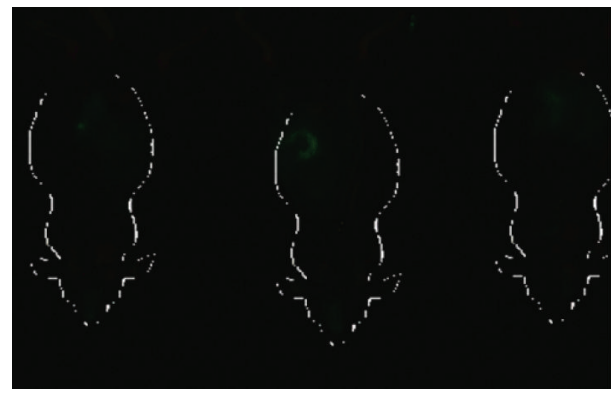

(d)

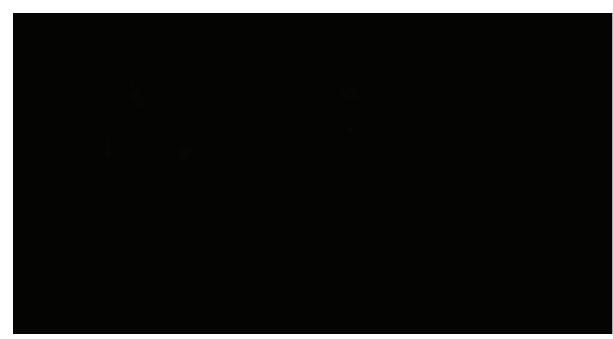

(f)

FIguRE 2: Biodistribution of ZM4-IR-dye. Three mice (1, 2, 3) were analyzed at 12 (a), 24 (b), 48 (c), and 72 (d) hours post ZM4-IR single administration. Fluorescence was visualized using the Odyssey Infrared Imaging System. Green fluorescence represents the IR signal ( $800 \mathrm{~nm}$ ) associated to the nanoparticle. The signal appears localized to the abdominal region (intestine) of the mouse. (e) Mice located on the mouse pod of the Odyssey scanner. (f) The image shows the absence of fluorescence signal in $m d x$ untreated mice.

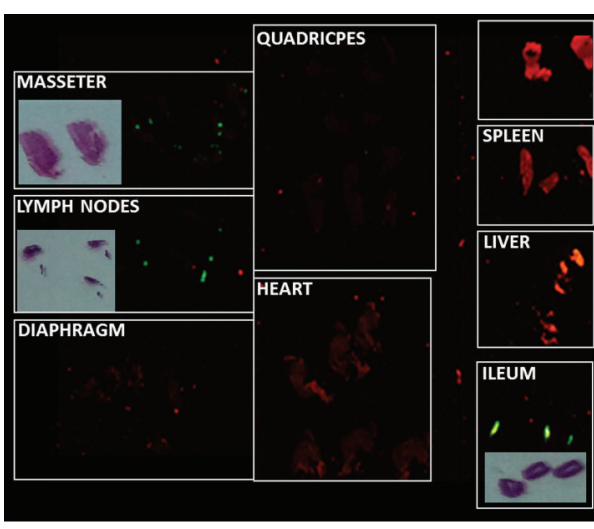

(a)

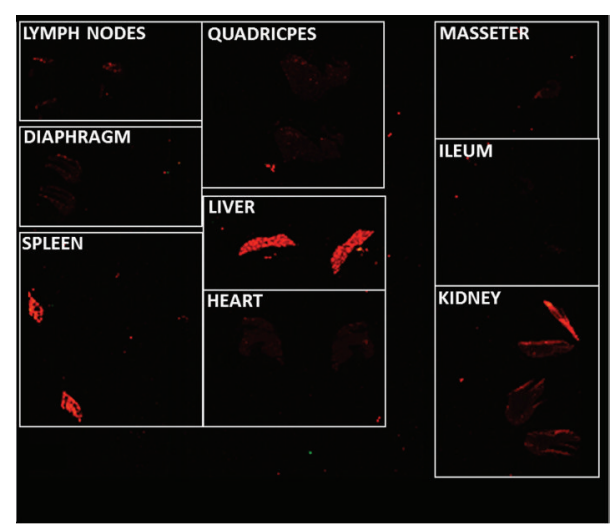

(b)

FIGURE 3: Odyssey analysis of organ/muscle cryosections $(20 \mu \mathrm{m})$ from ZM4-IR multiple-dose administered mice 7 days (a) and 1 month (b) after last treatment. Green fluorescence represents IR-dye signal $(\sim 800 \mathrm{~nm})$ associated to the nanoparticle; red represents tissue autofluorescence at $\sim 700 \mathrm{~nm}$. The signal is evident in abdominal lymph nodes, ileum, and masseter muscle at 7 days and absent at 1 month. Hematoxylin-Eosin (HE) staining of the same cryosections is presented next to IR positive sections to clarify the position on the slide. 
TABLE 2: Schedule of IR-dye conjugate nanoparticle treatments for biodistribution and elimination analysis.

\begin{tabular}{lcccc}
\hline $\begin{array}{l}\text { No. of } \\
\text { mice }\end{array}$ & Oral formulations & Frequency & No. of administration & Time of analysis \\
\hline$n=3$ & ZM4-IR $(2.5 \mathrm{mg})$ & 1/week & 1 & $\begin{array}{c}\text { Elimination (metabolic cages): 12 hours after administration } \\
\text { Time of collection of Odyssey images: 12-24-48-72 hours }\end{array}$ \\
\hline$n=3$ & ZM4-IR $(2.5 \mathrm{mg})$ & 2/week & 15 & $\begin{array}{c}\text { Time of collection of Odyssey images: before the new } \\
\text { administration }\end{array}$ \\
& & & Sacrifice: 1 week, 1 month after last administration \\
\hline
\end{tabular}

TABLE 3: Schedule of $m d x$ treatments for dystrophin restoration studies.

\begin{tabular}{|c|c|c|c|c|c|}
\hline & Oral formulations & Frequency & $\begin{array}{c}\text { No. of } \\
\text { administrations }\end{array}$ & Total dose & Time of analysis \\
\hline \multirow{2}{*}{$\begin{array}{l}\text { Group } 1 \\
\text { Alginate-free } \\
(n=6)\end{array}$} & $\begin{array}{c}\mathrm{ZM} 2(2.5 \mathrm{mg})-\mathrm{AON}(225 \mu \mathrm{g}) \\
(n=3)\end{array}$ & 2/week & 32 & $240 \mathrm{mg} / \mathrm{Kg}$ & 1 week after last administration \\
\hline & $\begin{array}{c}\mathrm{ZM} 2(2.5 \mathrm{mg}) \\
(n=3)\end{array}$ & 2/week & 32 & - & 1 week after last administration \\
\hline \multirow{2}{*}{$\begin{array}{l}\text { Group II } \\
\text { Alginate-coated } \\
(n=6)\end{array}$} & $\begin{array}{c}\mathrm{ZM} 2(2.5 \mathrm{mg})-\mathrm{AON}(200 \mu \mathrm{g}) \\
(n=3)\end{array}$ & 3/week & 36 & $240 \mathrm{mg} / \mathrm{Kg}$ & 1 week after last administration \\
\hline & $\begin{array}{c}\mathrm{ZM} 2(2.5 \mathrm{mg}) \\
(n=3)\end{array}$ & 3/week & 36 & - & 1 week after last administration \\
\hline $\begin{array}{l}\text { Group III } \\
\text { Untreated } \\
(n=3) \\
\end{array}$ & - & - & - & - & 1 week after last administration \\
\hline
\end{tabular}

with AON-free ZM2; $3 m d x$ mice were treated for 12 weeks (3 doses/week) with ZM2-M23D complexes coated with alginate; $3 m d x$ mice were treated for 12 weeks with alginate coated AON-free ZM2; 3 untreated mice were included as negative controls.

The amount of AON loaded onto alginate-coated ZM2 nanoparticles was lower with respect to the one used for ZM2 uncoated nanoparticles, $200 \mu \mathrm{g}$ versus $225 \mu \mathrm{g}$, in order to facilitate the interaction of the free surface positive charges of ZM2-AON complexes with alginate. For this reason the number of injections/week (2 versus 3 ) are different. However the total amount of M23D oligonucleotide received in each group of treatment was the same, represented by $240 \mathrm{mg} / \mathrm{kg}$. All groups of mice were sacrificed 1 week after the last administration.

The only side effect we observed was a mild laxative effect after the treatment with alginate formulations.

2.2.2. RNA Analysis. In order to test the effect of ZM2AON treatments on the dystrophin transcript, we assessed exon 23 skipping levels using a Real-Time PCR exon-specific assay (ESRA), as previously reported $[13,35]$. ESRAs were performed using the RNA pool for each treatment group and skipping percentages were calculated for the treated compared to the untreated mice. After 12 weeks of treatment with alginate-ZM2-AON, we only detected a low level of exon 23 skipping in the diaphragm of mice treated with alginatecoated ZM2-AON (mean skipping value for 3 mice, 8\%).
Exon-23 skipping was undetectable in the cardiac muscle, gastrocnemius, quadriceps and intestine for both ZM2-AON and alginate-ZM2-AON treated $m d x$ mice.

2.2.3. AON Hybridization Ligation Assay. To evaluate the presence and amount of AON in tissues, an AON sequencespecific hybridization ligation assay was performed. We analyzed the diaphragm from treated and untreated mice given that the diaphragm from alginate-ZM2-AON treated mice resulted positive in ESRA analysis ( $8 \%$ of skipping). To compare the data with a muscle that was negative in the ESRA analysis, we also analyzed the quadriceps from untreated and treated mice. The AON hybridization assay revealed the absence of AON both in diaphragm and quadriceps from all the treatments, probably due to the low amount of $\mathrm{AON}$ administered in our experiments $(240 \mathrm{mg} / \mathrm{kg})$ and M23D could be too low to be detectable by this assay (data not shown).

2.2.4. Immunofluorescence Analysis. In order to evaluate the presence and the correct localization of dystrophin, wild type (WT), treated and untreated $m d x$ sections were double labeled with a polyclonal antidystrophin antibody, followed by an antilaminin alpha 2 chain antibody for skeletal and cardiac muscles [36] and an antidesmin antibody for the intestine.

After 12 weeks of treatment with alginate ZM2-AON, immunofluorescence analysis revealed a slight rescue of dystrophin only in intestinal smooth muscle (Figure 4) and 

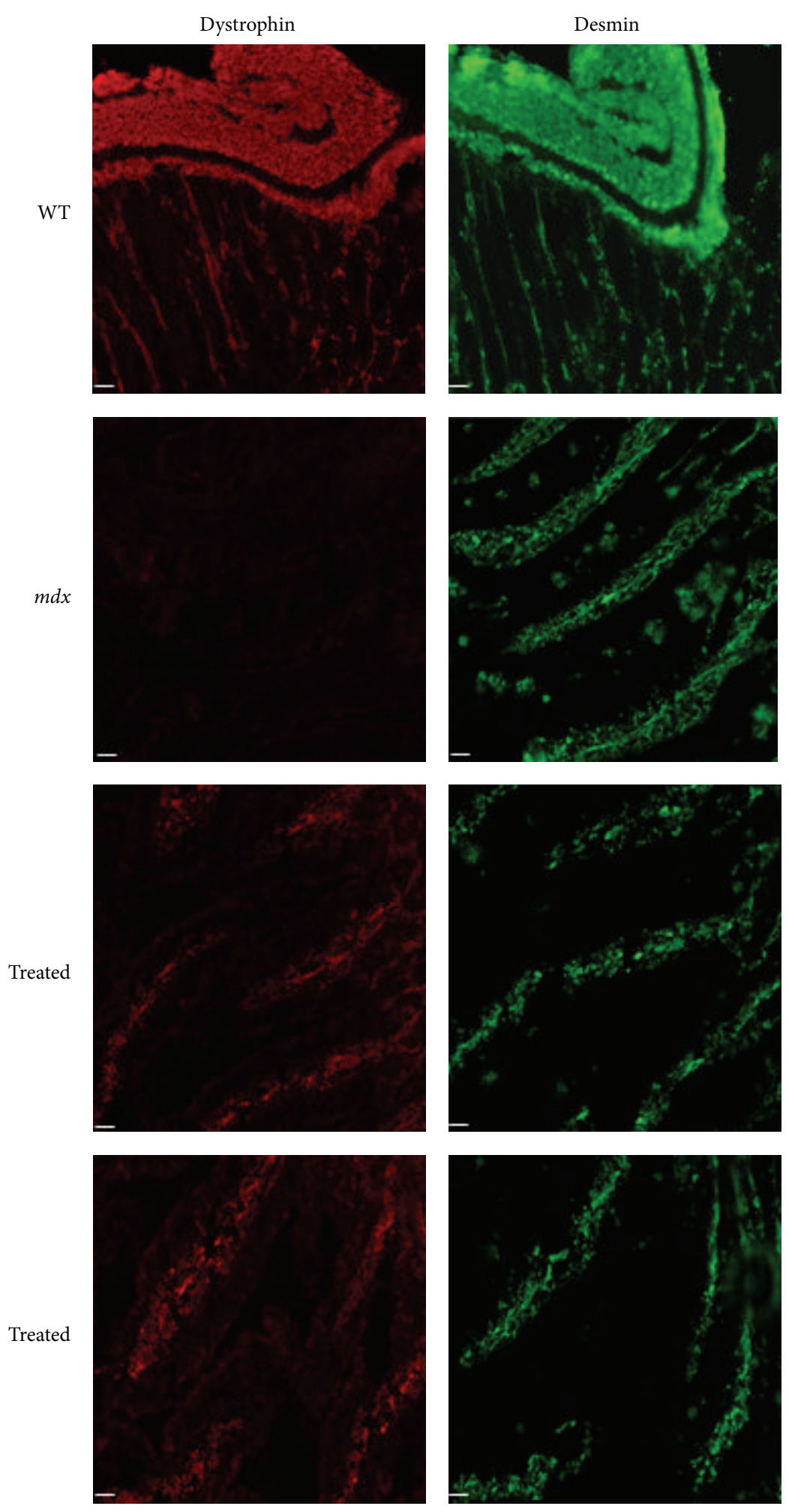

FIGURE 4: Immunofluorescence analysis of intestinal smooth muscle of wild type (WT), untreated $(m d x)$ and alginate-ZM2-M23D orally treated (Treated) $m d x$ mice. The sections of small intestine were labeled with antidystrophin antibody. Serial sections of intestine were labeled with a polyclonal antibody for desmin (green). All samples were observed with a Nikon Eclipse 80i fluorescence microscope. Dystrophin (red) is clearly visible in the intestinal smooth muscle of WT mice, absent in untreated $m d x$, and rescued in treated $m d x$ mice. (Scale bar $=50 \mu \mathrm{m}$ ). 
diaphragm (Figure 5); the latter result being consistent with the RNA data.

In mice treated with ZM2-AON alginate-free complexes, no dystrophin was detected in any of the muscles analyzed.

2.2.5. Western Blotting. Western blot analysis, performed as previously described [13], confirmed the presence of high molecular-weight dystrophin protein only in the intestine smooth muscle from alginate $\mathrm{ZM} 2-\mathrm{AON}$-treated mice (Figure 6).

For WT samples, the total protein loaded was 1/10 $(15 \mu \mathrm{g})$ of the quantity in the other lanes $(150 \mu \mathrm{g})$. Quantitation performed by densitometric analysis of autoradiographic bands followed by normalization with the quantity of total protein loaded on the gels showed $31 \pm 1.5 \%(P=0.0003)$ of dystrophin recovery in the intestine from alginate ZM2-AON treated mice with respect to WT mice controls. The results are representative of three separate experiments. Data are given as means \pm S.E.M.; statistical significance was calculated with the Student's $t$-test for unpaired data. No protein was detected in skeletal muscles (gastrocnemius, quadriceps, and diaphragm) or the heart of alginate ZM2-AON treated mice. No dystrophin was detected in tissues/muscles from all the other treated mice analyzed. The high $(31 \%)$ percentage of dystrophin in the smooth muscle of intestine, together with the positivity immunostaining, might be not surprising considering the oral administration route.

\section{Discussion}

In this work, we demonstrate that the oral route is very appealing as administration for AON and, more in general, drugs. The promising fact is the very low, but measurable, dystrophin rescue on the diaphragm that needs to be further studied to improve efficiency, reaching a remarkable dystrophin restoration. We believed that our data, although preliminary, might represent the first step for further studies aiming at delivering nanoparticle-AON orally.

Here, we reveal the biodistribution and elimination of orally administered NIR-dye marked NPs as well as the exon skipping efficacy of NPs combined with AON molecules in $m d x$ mice.

Preclinical studies and clinical trials $[1,4,5,7,37]$ have described the use of AONs limited to parenteral, intraperitoneal (i.p.), intravenous (i.v.), and subcutaneous (s.c.) routes $[13-15,19,38-40]$. To date, the oral route has received limited attention because it is known that AON-RNA molecules are subjected to the depurination process in the acidic gastric environment [22-25].

Here, we use alginate as an encapsulating agent for the oral formulation in order to protect the AON further, in addition to its combination with nanoparticles, against the gastric $\mathrm{pH}$ and to increase the intestinal adhesiveness of ZM2-AON complexes. Sodium alginate is biocompatible, biodegradable, nontoxic and approved by the US Food and Drug Administration for oral use [41-46]. It is also extensively used in food industry as a thickener, emulsifier and as a stabilizer [33]. Until now, alginates have been used for oral administration in preclinical models to encapsulate antitubercular drugs [43], hepatitis B antigen [47], pDNA coding for fish lymphocystis disease virus (LCDV) [48], insulin [49], the anti-inflammatory tripeptide Lys-Pro-Val (KPV) to treat inflammatory bowel disease (IBD) [50], oral DNA vaccine against infectious pancreatic necrosis virus [51], and antisense DNA oligonucleotides [46].

Alginate has never been used as a protective agent for exon-skipping inducing RNA molecules systemic delivery.

After a single oral administration, ZM4 remains in the intestine for about 72 hours, before being adsorbed and/or eliminated. The imaging in live animals before each dose of the multiple treatment shows the absence of NP accumulation. Adsorption through the intestinal wall is demonstrated by Odyssey cryosection analysis showing ZM4 in abdominal lymph nodes one week after treatment; no ZM4 was detected in the organs of mice sacrificed 1 month after the last administration. ZM4 clearance studies reveal that they are eliminated almost exclusively through feces and mainly in the first 48 hours after administration. This result suggests that the positivity observed in the intestine 72 hours after administration is represented by a low percentage (10\%) of residual ZM4 and that the biodistribution evaluation could be affected by this early elimination of the majority of the administered NPs. Furthermore, in this context, the potential functional effect of NP-AON complexes in terms of dystrophin protein rescue could be reduced by the low amount of systemically available therapeutic molecules.

Following the verification of the intestinal absorption of the ZM4 we continued to demonstrate that oral treatment with NP-AON complexes is able to restore dystrophin synthesis, though at very low level, in $m d x$ mice. The comparison between two different treatments, one with ZM2-AON complexes encapsulated with alginate and the other with alginate-free ZM2-AON complexes, reveals that the alginate is necessary to protect the $\mathrm{AON}$ molecules, maintaining their ability to recover the dystrophin protein.

Our data demonstrate that only in $m d x$ mice orally treated with alginate-coated ZM2-AON complexes there is a slight rescue of dystrophin protein in the intestinal smooth muscles and a weak positivity in the diaphragm. No dystrophin was detected, on the other hand, in any of the muscles of mice treated with alginate-free ZM2-AON complexes. Table 4 summarizes the dystrophin restoration results.

It is known that dystrophin is present in several cell types in the gastrointestinal wall, in smooth muscle cells (SMCs) of the muscularis externa and muscularis mucosae, in the myoid cells located in the mucosa, in the perivascular SMCs, and all the submucous and myenteric neurons [52]. On the contrary, full-length dystrophin is lacking in the gastrointestinal tract of DMD patients and $m d x$ mice, which show several alterations in gastrointestinal motility.

Notably, our results give the first evidence that the oral delivery of an antisense oligoribonucleotide co-formulated with ZM2 and alginate can produce a functional effect on RNA splicing. We observe that the protective action of the alginate is essential for preventing damage to the AON molecules by gastric acid since only with alginate-coated ZM2-AON we observe dystrophin synthesis, showing that 

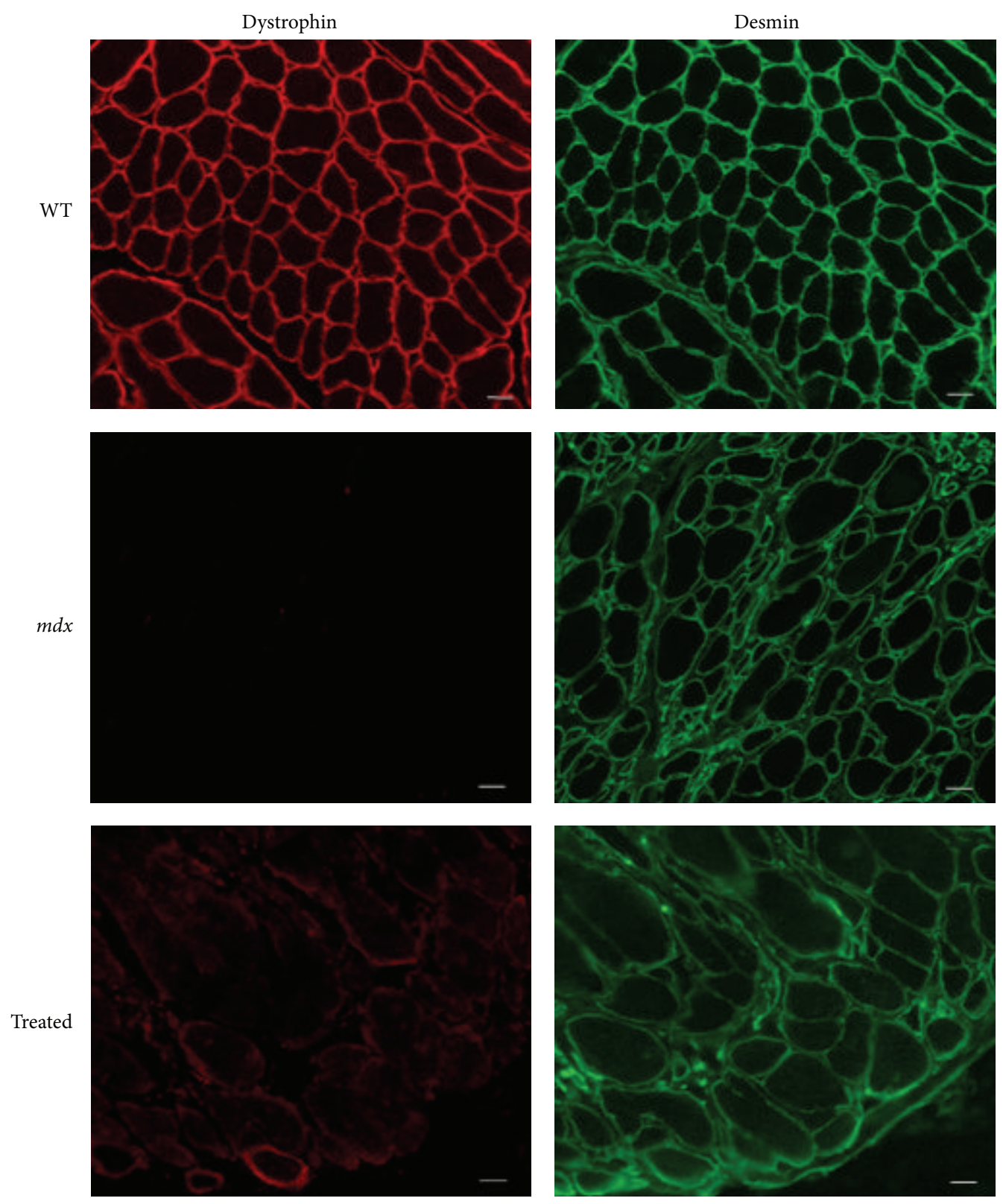

FIGURE 5: Immunofluorescence analysis of dystrophin protein in the diaphragm of wild type (WT), untreated ( $m d x$ ), and alginate-ZM2M23D orally treated (treated) $m d x$ mice. The sections were labeled with antidystrophin antibody (red signal) and double-labeled with a rat monoclonal antibody for laminin-2 (green). Dystrophin traces are visible in diaphragm from alginate ZM2-M23D oral treated mice. No dystrophin labeling was detected at the sarcolemma in mice untreated or treated with ZM2-AON $m d x$. (Scale bar $=50 \mu \mathrm{m})$.

ZM2 alone are not sufficient for AON protection. The low efficiency on the restoration of dystrophin protein might be due to the inability of ZM2 to efficiently overcome the intestinal barrier, as documented by the biodistribution studies by Odyssey. Concomitantly, the observed laxative effect of alginate may result in a reduced amount of available ZM2AON complexes and a consequent decrease in the contact time between particles and the intestinal epithelium, leading to a lower uptake of the molecules. AON specific ELISA concordantly demonstrated the absence of $\mathrm{AON}$ in mice tissues.
Nonetheless, some AONs are protected enough to pass the body barriers and reach at least the diaphragm with measurable functional effect.

Smaller size or/and modified hydrophilicity of NPs and AON chemical modifications may also improve the in vivo biodistribution and stability of the binding with NPs-AON and therefore deserve to be addressed. In conclusion, the challenge for future studies will be to improve both the AON structure (backbone) and molecule protection by NPs to improve the AON bioavailability and 
TABLE 4: Summary of results of dystrophin restoration studies.

\begin{tabular}{|c|c|c|c|c|c|}
\hline & Oral formulations & Tissues & $\begin{array}{c}\text { Exon } 23 \text { skipping } \\
\% \\
\end{array}$ & IHC & WB \\
\hline \multirow{10}{*}{$\begin{array}{l}\text { Group I } \\
\text { No alginate } \\
(n=6)\end{array}$} & \multirow{5}{*}{$\begin{array}{l}\mathrm{ZM} 2(2.5 \mathrm{mg})-\mathrm{AON}(225 \mu \mathrm{g}) \\
(n=3)\end{array}$} & Diaphragm & 0 & - & - \\
\hline & & Intestine & 0 & - & - \\
\hline & & Gastrocnemius & 0 & - & - \\
\hline & & Quadriceps & 0 & - & - \\
\hline & & Heart & 0 & - & - \\
\hline & \multirow{5}{*}{$\begin{array}{l}\mathrm{ZM} 2(2.5 \mathrm{mg}) \\
(n=3)\end{array}$} & Diaphragm & 0 & - & - \\
\hline & & Intestine & 0 & - & - \\
\hline & & Gastrocnemius & 0 & - & - \\
\hline & & Quadriceps & 0 & - & - \\
\hline & & Heart & 0 & - & - \\
\hline \multirow{10}{*}{$\begin{array}{l}\text { Group II } \\
\text { +alginate } \\
(n=6)\end{array}$} & \multirow{5}{*}{$\begin{array}{l}\mathrm{ZM} 2(2.5 \mathrm{mg})-\mathrm{AON}(200 \mu \mathrm{g}) \\
(n=3)\end{array}$} & Diaphragm & 8 & + & - \\
\hline & & Intestine & 0 & + & + \\
\hline & & Gastrocnemius & 0 & - & - \\
\hline & & Quadriceps & 0 & - & - \\
\hline & & Heart & 0 & - & - \\
\hline & \multirow{5}{*}{$\begin{array}{l}\mathrm{ZM} 2(2.5 \mathrm{mg}) \\
(n=3)\end{array}$} & Diaphragm & 0 & - & - \\
\hline & & Intestine & 0 & - & - \\
\hline & & Gastrocnemius & 0 & - & - \\
\hline & & Quadriceps & 0 & - & - \\
\hline & & Heart & 0 & - & - \\
\hline \multirow{5}{*}{$\begin{array}{l}\text { Group III } \\
\text { Untreated } \\
(n=3)\end{array}$} & \multirow{5}{*}{-} & Diaphragm & 0 & - & - \\
\hline & & Intestine & 0 & - & - \\
\hline & & Gastrocnemius & 0 & - & - \\
\hline & & Quadriceps & 0 & - & - \\
\hline & & Heart & 0 & - & - \\
\hline
\end{tabular}

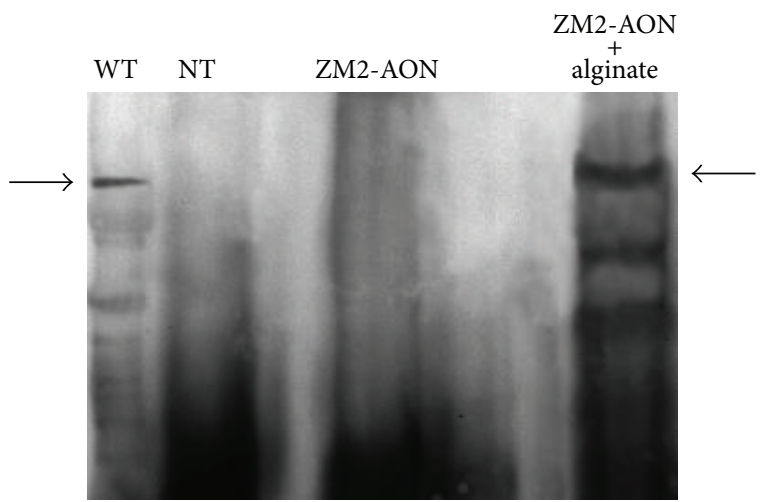

FIGURE 6: Immunoblotting of dystrophin in the intestine of untreated $m d x$ mice (NT), ZM2-AON treated mice, and alginatecoated ZM2-AON treated mice. Intestine from WT mice were used as positive controls. For WT samples, the total protein loaded was $1 / 10(15 \mu \mathrm{g})$ of the quantity used in the other lanes $(150 \mu \mathrm{g})$. Quantitation performed by densitometric analysis of autoradiographic bands followed by normalization with the quantity of total protein loaded on the gels showed $31 \pm 1.5 \%(P=0.0003)$ of dystrophin recovery in the intestine from alginate $\mathrm{ZM} 2-\mathrm{AON}$-treated mice compared to WT mice. The arrows show the bands of dystrophin $(427 \mathrm{kD})$. to enhance the intestinal cells' uptake of orally delivered drugs.

\section{Materials and Methods}

4.1. Animals. All experiments were performed on male $m d x$ mice $(\mathrm{C} 57 \mathrm{BL} / 10 \mathrm{ScSn}-\mathrm{Dmd} m d x / \mathrm{J})$. All procedures were approved by the Animal Experimentation Ethics Committee. Mice were housed in temperature-controlled rooms $\left(22^{\circ} \mathrm{C}\right)$ at a humidity level of 50\% and a 12:12 hour light-dark cycle. Mice were purchased from the Jackson Laboratory (Bar Harbor, $\mathrm{ME})$.

4.2. ZM4 Nanoparticles Synthesis. ZM4 nanoparticle sample were prepared by emulsion polymerization of methyl methacrylate employing as emulsion stabilizers, different functional comonomers (N-isopropyl acrylamide (NIPAM), (N,Ndimethyl N-octyl ammonium) ethyl methacrylate bromide (MOAEMA) and 2-aminoethyl methacrylate hydrochloride (AEMA)).

In particular, $30.0 \mathrm{~mL}$ of methyl methacrylate were introduced in a flask containing $500 \mathrm{~mL}$ of an aqueous solution 
of $2.34 \mathrm{~g}(6.7 \mathrm{mmol})$ of MOAEMA, $0.55 \mathrm{~g}(3.3 \mathrm{mmol})$ of AEMA and $1.13 \mathrm{~g}(10 \mathrm{mmol})$ NIPAM. The flask was fluxed with nitrogen under constant stirring for 30 minutes, then $85 \mathrm{mg}(0.313 \mathrm{mmol})$ of the cationic free radical initiator AIBA, dissolved in water, were added. The polymerization was performed at $80 \pm 1.0^{\circ} \mathrm{C}$ for 4 hours under constant stirring. At the end of the reaction, the samples were recovered and purified by repeated dialysis.

Particle sizes and size distributions were measured by dynamic light scattering and scanning electron microscopy (SEM) analysis. Dynamic light scattering analysis was performed at $25^{\circ} \mathrm{C}$, with a Malvern Zetasizer Nano ZS system at a fixed scattering angle of $90^{\circ}$, using a He-Ne laser and a PCS software (Malvern, U.K., version 6.11). Five individual measurements were performed for each sample. The values that we report are the average of these 5 measurements. SEM analysis were performed with a Field Emission Gun Inspect F microscope from FEI Company. The SEM micrographs were elaborated by the Scion Image processing (NIH, public domain) program. From 200 to 250 individual nanospheres were measured for each sample. The characteristics of the obtained nanoparticles are reported in Table 1.

4.3. ZM4 Conjugation with NIR-797 Dye. $1,2 \mathrm{~mL}$ of a solution $3 \mathrm{mg} / \mathrm{mL}$ of dye NIR-797 Isothiocyanate (Sigma-Aldrich, $\lambda_{\mathrm{ex}}$ $\left.795 \mathrm{~nm} ; \lambda_{\mathrm{em}} 817 \mathrm{~nm}\right)$ in anhydrous DMSO were added to $15 \mathrm{~mL}$ of a suspension of nanoparticles $(22 \mu \mathrm{g}$ NIR-797/mg nanoparticle) in phosphate buffer $(10 \mathrm{mM}, \mathrm{pH} 8)$ under magnetic stirring for 2 hours protected from light. After centrifugation (10 minutes at $11000 \mathrm{~g}$ ) the pellet was washed twice, then resuspended in water obtaining ZM4-IR nanoparticles.

4.4. Oral Administration Schedule for Biodistribution and Elimination Studies. $2.5 \mathrm{mg}$ of ZM4-IR NPs dissolved in $200 \mu \mathrm{L}$ of water, were administered to mice by oral gavage in single or multiple treatments. 8-6 weeks old $m d x$ mice were divided into 2 groups $(n=2)$ of treatment: the first group received a single dose of $\mathrm{ZM} 4-\mathrm{IR}$, the second group received 2 administrations/week for a total of 15 administrations of ZM4-IR. Table 2 summarizes the administration schedule. Two untreated mice were used as negative controls.

4.5. Biodistribution and Elimination Studies. Prior to the acquisition of in vivo images, the mice were fed with a special diet (Research Diets AIN-76A or AIN-93G) in order to minimize autofluorescence (red signal) due to chlorophyll contained in plant-based ingredients. The animals were anesthetized with $1 \%$ Avertin, shaved in abdominal and chest regions and located on MousePod of Odyssey for infrared in vivo imaging. The scanning was performed $12,24,48,72$ hours after a single administration of ZM4-IR and before each dose for multiple administrations. For nanoparticles clearance studies mice were placed into metabolic cages for collecting feces and urine for 24 hours starting after 12 hours and 6 days after ZM4-IR administration. The feces were weighed and then dissolved in $4 \mathrm{~mL}$ of PBS by vigorous shaking, while the urine samples were spin for 10 minutes at $11000 \mathrm{~g}$ and solubilized in $100 \mu \mathrm{L}$. The total urine sample
(100 $\mu \mathrm{L}), 100 \mu \mathrm{L}$ of feces suspension and progressive dilutions of both samples were put in a 96 well-dish and analyzed by Odyssey. Along with samples a dilution of the fluorescent nanoparticles were prepared as a standard. To perform quantification of signals, regions of interest (ROIs) of equal size were drawn and placed over each well. A calibration curve was obtained from the dilution of the fluorescent nanoparticles after normalization of each ROI to the sum of the total intensity of all the standard ROIs. The same normalization procedure was applied to the feces and urine samples and normalized values were used.

At the end of treatments, mice were sacrificed, their tissues and organs excised, frozen in liquid N2-cooled isopentane, and stored at $-80^{\circ} \mathrm{C}$. Twenty-micrometer-thick frozen transverse sections were cut from different specimens, analyzed by Odyssey and stained with hematoxylin and eosin (H\&E) (Sigma-Aldrich, Milan, Italy).

4.6. AON Synthesis. M23D(+07-18) (5'-GGCCAAACCUCGGCUUACCUGAAAU- $3^{\prime}$ ) AON against the boundary sequences of the exon and intron 23 of mouse dystrophin gene, contains $2^{\prime}$-O-methyl modified RNA and full-length phosphorothioate backbone. Oligonucleotide synthesis was carried out on an ÄKTA oligopilot plus 10 DNA/RNA synthesizer (GE Healthcare, Milano, Italy) using its trityl-on mode. The sequence was synthesized on a $2 \mu \mathrm{mol}$ scale using Primer Support 200 loaded at $80 \mu \mathrm{mol} / \mathrm{g}$ (Amersham Biosciences, Milano, Italy). Commercial $2^{\prime}$-O-methyl phosphoramidites (Proligo, Boulder, CO) were dissolved to a nominal concentration of $50 \mathrm{mmol} / \mathrm{L}$ in anhydrous acetonitrile $\left(\mathrm{CH}_{3} \mathrm{CN}\right)$ and activated with a $0.25 \mathrm{~mol} / \mathrm{L}$ solution of 5 -(bis-3,5-trifluoromethylphenyl)-1H-tetrazole (Proligo) in $\mathrm{CH}_{3} \mathrm{CN}$. The final detritylation was achieved using a $0.1 \mathrm{~mol} / \mathrm{L}$ aqueous solution of $\mathrm{NaOAc}(\mathrm{pH} 3.0)$. Crude dimethyltryptamine protected and detritylated oligonucleotide were purified by an ÄKTAbasic ultraphysical contact liquid chromatography system using an Amersham Biosciences Resource RPC $3 \mathrm{~mL}$ column eluted under a gradient of $\mathrm{CH}_{3} \mathrm{CN}$ in $0.1 \mathrm{~mol} / \mathrm{L}$ triethylammonium acetate ( $\mathrm{pH} 8)$. The final oligonucleotide was dissolved in water and filtered through a short column of Dowex 50WX8 ( $\mathrm{Na}^{+}$form, 100-200 mesh) to obtain after lyophilization $0.8 \mu \mathrm{mol}(40 \%)$ of target compound. The purity of the fulllength desired product was evaluated by MALDI-TOF MS, 31P-NMR and RP-HPLC analyses.

4.7. ZM2-M23D Loading. ZM2 nanoparticles were prepared by emulsion polymerization of methyl methacrylate employing, as emulsion stabilizers, two functional comonomers (N-isopropyl acrylamide (NIPAM) and (N,N-dimethyl Noctyl ammonium) ethyl methacrylate bromide) as previously reported [14]. They have a particle diameter of $137 \mathrm{~nm}$ (as determined by scanning electron microscopy) and a surface charge density of $202 \mu \mathrm{mol}$ ammonium groups per gram of nanoparticles. M23D AON contains $2^{\prime}$-O-methyl RNA phosphorothioate backbone and its synthesis was previously described [13]. Loading experiments have shown that ZM2 nanoparticles $(1 \mathrm{mg} / \mathrm{mL})$ adsorbed $2^{\prime}$ OMePS M23D oligoribonucleotide onto their surface in the concentration range of $10-100 \mu \mathrm{g} / \mathrm{mL}$. M23D adsorption onto ZM2 nanoparticles 
is a highly reproducible process with a loading value of $90 \mu \mathrm{g} / \mathrm{mg}[14]$.

4.8. Naked ZM2 or ZM2-AON Coating with Alginate. Suspension of naked ZM2 or ZM2-AON complexes in water were mixed with a solution of sodium alginate $(0.52 \mathrm{mg}$ alginate/mg of ZM2) under magnetic stirring for 10 minutes. $\mathrm{CaCl}_{2}(3 \mathrm{mM})$ was added to the solution and kept under agitation for 10 additional minutes. After centrifugation at $11000 \mathrm{~g}$ for 15 minutes the supernatant was removed and collected in new tubes, while alginate-ZM2 or alginate ZM2AON $(200 \mu \mathrm{g}$ AON/2.5 mg ZM2) pellets were loaded in insulin syringes for oral administration by gavage. The collected supernatants were drawn, filtered on a Millex $\mathrm{GV}_{4}$ filter and the absorbance $(260-280 \mathrm{~nm})$ measured by Nanodrop 1000 (Thermo Scientific).

4.9. Oral Administration Schedule for Dystrophin Restoration Studies. Two groups of $m d x$ mice (6 weeks old) were treated by oral gavage. The I group received $200 \mu \mathrm{L}$ of suspension containing $225 \mu \mathrm{g}$ of M23D loaded onto $2.5 \mathrm{mg}$ of ZM2 nanoparticles ( 3 mice) or $2.5 \mathrm{mg}$ of AON-free ZM2 nanoparticles as negative control (3 mice) for a total of 32 administrations $(240 \mathrm{mg} / \mathrm{Kg}$ total). The II group was treated with $200 \mu \mathrm{L}$ of suspension containing $200 \mu \mathrm{g}$ of M23D loaded onto $2.5 \mathrm{mg}$ of ZM2 nanoparticles or $2.5 \mathrm{mg}$ of AON-free ZM2 nanoparticles but in the presence of alginate $(3$ mice for each different treatment) for a total of 36 administrations $(240 \mathrm{mg} / \mathrm{Kg}$ total). Three untreated age-matched $m d x$ mice were included as negative controls. All groups of mice were sacrificed 1 week after last administration.

Table 3 summarizes the administration schedule.

4.10. Dystrophin RNA Studies. Total RNA was extracted from frozen sections of muscle biopsies using TRIzol (Invitrogen, Milano, Italy), and reverse-transcribed into cDNA using the High-Capacity cDNA Reverse Transcription kit (Applied Biosystems, Frankfurt, Germany). We performed ExonSpecific Real Time Assays (ESRAs) using RNA pool for each treatment group. ESRAs were used on exons 8, 23, and 25 to quantify the percentage of exon-23 skipping in treated, with respect to untreated mice ( $\Delta \mathrm{Ct}$ method), using $\beta$-actin as endogenous control. All these ESRAs are based on TaqMan technology and have been designed by PrimerExpress Applied Biosystems software (Applied Biosystems). Primers and probes sequences are available upon request. The amount of target sequences compared to appropriate endogenous control ( $\beta$-actin gene) was evaluated by the comparative CT method with respect to the endogenous $\beta$-actin control $(\Delta \Delta \mathrm{Ct}$ Method) (Applied Biosystems User Bulletin no. 2) $[13,53]$.

4.11. AON Hybridization Ligation Assay. The assay for measuring the concentration of $2 \mathrm{OMePS}$ oligoribonucleotide $23 \mathrm{AON}$ in tissue samples is based on a hybridization ligation assay [38]. A template probe ( $5^{\prime}$-gaatagacgaggtaagccgaggtttggcc-biotin-3', 29-mer DNA phosphate oligonucleotide) and a ligation probe (5'-P-cgtctattc-DIG-3', 9-mer DNA phosphate oligonucleotide) were used. The sample was incubated with the template probe $(50 \mathrm{nmol} / \mathrm{L})$ at $37^{\circ} \mathrm{C}$ for 1 hour, and the hybridized samples were transferred to streptavidincoated 96-well plates. Subsequently, the digoxigenin-labeled ligation probe $(2 \mathrm{nmol} / \mathrm{L})$ was added. Detection was performed with anti-DIG-POD (1:4,000; Roche Diagnostics, Milan, Italy), 3,3' ${ }^{\prime}, 5,5^{\prime}$-tetramethylbenzidine substrate (Sigma Aldrich S.r.l, Milan, Italy), and stop solution (Sigma Aldrich). Absorption at $450 \mathrm{~nm}$ was measured in a SpectraFluorPlus (Tecan Italia Srl, Cernusco sul Naviglio, Milan, Italy). The tissue samples were homogenized to a concentration of $60 \mathrm{mg} / \mathrm{mL}$ in proteinase $\mathrm{K}$ buffer $(100 \mathrm{mmol} / \mathrm{L}$ Tris- $\mathrm{HCl}$, $\mathrm{pH} 8.5,200 \mathrm{mmol} / \mathrm{L} \mathrm{NaCl}, 5 \mathrm{mmol} / \mathrm{L}$ EDTA, $0.2 \%$ sodium dodecylsulfate) containing $2 \mathrm{mg} / \mathrm{mL}$ of proteinase $\mathrm{K}$ (Life Technologies, Monza, Italy), followed by incubation for 4 hours rotating at $55^{\circ} \mathrm{C}$ in a hybridization oven. Next, the samples were centrifuged for 15 minutes at maximum speed and the supernatant was used in the assay. We analyzed diaphragm and quadriceps from untreated and oral treated $m d x$ mice. Muscle samples were first diluted 60-fold in PBS, subsequent dilutions and the calibration curves were done in 60 -fold control muscle in PBS.

4.12. Dystrophin Protein Immunofluorescence Analysis. One week after the last injection, $m d x$ mice were killed, and their diaphragm, quadriceps, gastrocnemius, cardiac muscles and intestine isolated, snap-frozen in liquid N2-cooled isopentane and stored at $-80^{\circ} \mathrm{C}$ until further processing.

Seven-micrometer-thick frozen transverse sections were cut from at least two-thirds of the length of heart, diaphragm, gastrocnemius, quadriceps muscles and intestine; for each muscle at least 5 slices were cut at $150 \mu \mathrm{m}$ intervals. To analyze dystrophin restoration freshly-cut muscle and intestine sections were labeled with a polyclonal antidystrophin antibody (H-300) (epitope corresponding to amino acids 801-1100 mapping within an internal region of dystrophin; Santa Cruz Biotechnology, Santa Cruz, CA) diluted 1:100 revealed with anti-rabbit Cy3-conjugated secondary antibody (Jackson Immunoresearch, Suffolk, UK). Muscles samples were double-labeled with a rat monoclonal antibody for laminin-2 ( $\alpha 2$-chain, 4H8-2, diluted 1:500; Alexis Biochemical, Farmingdale, NY, USA) revealed with anti-rat Cy2-conjugated secondary antibody (Jackson Immunoresearch, Suffolk, UK). Seriate sections of intestine were labeled with a polyclonal antibody for desmin (diluted 1:100, Abcam, Cambridge, UK) followed by anti-rabbit FITC-conjugated secondary antibody for desmin (DAKO, Glostrup, Denmark). All images were observed with a Nikon Eclipse 80i fluorescence microscope (Nikon Instruments, Firenze, Italy) connected to at a highresolution CCD camera (Nikon Instruments, Firenze, Italy) at 20x magnification.

4.13. Dystrophin Analysis by Western Blotting. Western blot analysis was performed as previously described [13]. Twentymicrometer-thick frozen muscle sections were homogenized with a lysis buffer $(7 \mathrm{~mol} / \mathrm{L}$ urea, $2 \mathrm{~mol} / \mathrm{L}$ thiourea, $1 \%$ amidosulfobetaine-14, and $0.3 \%$ dithioerythritol). Aliquots of proteins from wild type mice $(15 \mu \mathrm{g})$ and from the muscles of treated or untreated $m d x$ mice $(150 \mu \mathrm{g})$ were loaded onto a $6 \%$ sodium dodecyl sulphate-polyacrylamide gel and separated 
by electrophoresis. Samples were transferred to a nitrocellulose membrane at $75 \mathrm{~V}$. The membrane was incubated overnight at $4^{\circ} \mathrm{C}$ with the specific antibody DYS2 (NovoCastra, Newcastle, UK).

To quantify the restoration of dystrophin protein in treated versus wild type mice, a densitometric analysis of autoradiographic bands was performed with a Bio-Rad Densitometer GS 700 (Bio-Rad, Milan, Italy), followed by normalization with the quantity of total protein loaded onto the gels.

\section{Conflict of Interests}

The authors declared no conflict of interests.

\section{Acknowledgments}

The Telethon Italy Grant GGP09093 (to A. Ferlini, Department of Medical Science, Section of Medical Genetics, University of Ferrara, Ferrara, Italy) is acknowledged. The authors are grateful to Judith CT van Deutekom (Prosensa Therapeutics B.V., Leiden) for her help and suggestions with AON hybridization ligation assay.

\section{References}

[1] J. C. van Deutekom, A. A. Janson, I. B. Ginjaar et al., "Local dystrophin restoration with antisense oligonucleotide PRO051," The New England Journal of Medicine, vol. 357, no. 26, pp. 26772686, 2007.

[2] S. D. Wilton and S. Fletcher, "Exon skipping and Duchenne muscular dystrophy: hope, hype and how feasible?" Neurology India, vol. 56, no. 3, pp. 254-262, 2008.

[3] G. J. van Ommen, J. van Deutekom, and A. Aartsma-Rus, “The therapeutic potential of antisense-mediated exon skipping," Current Opinion in Molecular Therapeutics, vol. 10, no. 2, pp. 140-149, 2008.

[4] N. M. Goemans, M. Tulinius, J. T. van den Akker et al., "Systemic administration of PRO051 in Duchenne's muscular dystrophy," The New England Journal of Medicine, vol. 364, no. 16, pp. 1513-1522, 2011.

[5] S. Cirak, V. Arechavala-Gomeza, M. Guglieri et al., "Exon skipping and dystrophin restoration in patients with Duchenne muscular dystrophy after systemic phosphorodiamidate morpholino oligomer treatment: an open-label, phase 2, doseescalation study," The Lancet, vol. 378, no. 9791, pp. 595-605, 2011.

[6] http://www.clinicaltrials.gov/ct2/results?term=NCT01396239.

[7] M. Kinali, V. Arechavala-Gomeza, L. Feng et al., "Local restoration of dystrophin expression with the morpholino oligomer AVI-4658 in Duchenne muscular dystrophy: a single-blind, placebo-controlled, dose-escalation, proof-of-concept study," The Lancet Neurology, vol. 8, no. 10, pp. 918-928, 2009.

[8] http://www.clinicaltrials.gov/ct2/results?term=DMD\&pg=2 .

[9] W.-H. Pan and G. A. Clawson, "Antisense applications for biological control," Journal of Cellular Biochemistry, vol. 98, no. 1, pp. 14-35, 2006.
[10] C. F. Bennett and E. E. Swayze, "RNA targeting therapeutics: molecular mechanisms of antisense oligonucleotides as a therapeutic platform," Annual Review of Pharmacology and Toxicology, vol. 50, pp. 259-293, 2010.

[11] V. Arora, D. C. Knapp, M. T. Reddy, D. D. Weller, and P. L. Iversen, "Bioavailability and efficacy of antisense Morpholino oligomers targeted to c-myc and cytochrome P-450 3A2 following oral administration in rats," Journal of Pharmaceutical Sciences, vol. 91, no. 4, pp. 1009-1018, 2002.

[12] C. J. Mann, K. Honeyman, A. J. Cheng et al., "Antisense-induced exon skipping and synthesis of dystrophin in the $m d x$ mouse," Proceedings of the National Academy of Sciences of the United States of America, vol. 98, no. 1, pp. 42-47, 2001.

[13] P. Rimessi, P. Sabatelli, M. Fabris et al., "Cationic PMMA nanoparticles bind and deliver antisense oligoribonucleotides allowing restoration of dystrophin expression in the $m d x$ mouse," Molecular Therapy, vol. 17, no. 5, pp. 820-827, 2009.

[14] A. Ferlini, P. Sabatelli, M. Fabris et al., "Dystrophin restoration in skeletal, heart and skin arrector pili smooth muscle of $m d x$ mice by ZM2 NP-AON complexes," Gene Therapy, vol. 17, no. 3, pp. 432-438, 2010.

[15] E. Bassi, S. Falzarano, M. Fabris et al., "Persistent dystrophin protein restoration 90 days after a course of intraperitoneally administered naked 2' OMePS AON and ZM2 NP-AON complexes in $m d x$ mice," Journal of Biomedicine and Biotechnology, vol. 2012, Article ID 897076, 8 pages, 2012.

[16] P. Sicinski, Y. Geng, A. S. Ryder-Cook, E. A. Barnard, M. G. Darlison, and P. J. Barnard, "The molecular basis of muscular dystrophy in the $m d x$ mouse: a point mutation," Science, vol. 244, no. 4912, pp. 1578-1580, 1989.

[17] E. P. Hoffman, R. H. Brown Jr., and L. M. Kunkel, "Dystrophin: the protein product of the Duchenne muscular dystrophy locus," Cell, vol. 51, no. 6, pp. 919-928, 1987.

[18] E. P. Hoffman, J. E. Morgan, S. C. Watkins, and T. A. Partridge, "Somatic reversion/suppression of the mouse $m d x$ phenotype in vivo," Journal of the Neurological Sciences, vol. 99, no. 1, pp. 9-25, 1990.

[19] L. L. Qi, A. Rabinowitz, Y. C. Chen et al., "Systemic delivery of antisense oligoribonucleotide restorers dystrophin expression in body-wide skeletal muscles," Proceedings of the National Academy of Sciences of the United States of America, vol. 102, no. 1, pp. 198-203, 2005.

[20] J. Xu, S. Ganesh, and M. Amiji, "Non-condensing polymeric nanoparticles for targeted gene and siRNA delivery," International Journal of Pharmaceutics, vol. 427, no. 1, pp. 21-34, 2012.

[21] S. Akhtar, "Oral delivery of siRNA and antisense oligonucleotides," Journal of Drug Targeting, vol. 17, no. 7, pp. 491-495, 2009.

[22] A. A. Raoof, P. Chiu, Z. Ramtoola et al., "Oral bioavailability and multiple dose tolerability of an antisense oligonucleotide tablet formulated with sodium caprate," Journal of Pharmaceutical Sciences, vol. 93, no. 6, pp. 1431-1439, 2004.

[23] R. S. Geary, O. Khatsenko, K. Bunker et al., "Absolute bioavailability of $2^{\prime}$-O-(2-methoxyethyl)-modified antisense oligonucleotides following intraduodenal instillation in rats," Journal of Pharmacology and Experimental Therapeutics, vol. 296, no. 3, pp. 898-904, 2001.

[24] A. des Rieux, V. Fievez, M. Garinot, Y.-J. Schneider, and V. Préat, "Nanoparticles as potential oral delivery systems of proteins and vaccines: a mechanistic approach," Journal of Controlled Release, vol. 116, no. 1, pp. 1-27, 2006. 
[25] S. Maher, T. W. Leonard, J. Jacobsen, and D. J. Brayden, "Safety and efficacy of sodium caprate in promoting oral drug absorption: from in vitro to the clinic," Advanced Drug Delivery Reviews, vol. 61, no. 15, pp. 1427-1449, 2009.

[26] L. G. Tillman, R. S. Geary, and G. E. Hardee, "Oral delivery of antisense oligonucleotides in man," Journal of Pharmaceutical Sciences, vol. 97, no. 1, pp. 225-236, 2008.

[27] L. Yin, J. Ding, J. Zhang, C. He, C. Tang, and C. Yin, "Polymer integrity related absorption mechanism of superporous hydrogel containing interpenetrating polymer networks for oral delivery of insulin," Biomaterials, vol. 31, no. 12, pp. 3347-3356, 2010.

[28] R. M. Samstein, K. Perica, F. Balderrama, M. Look, and T. M. Fahmy, "The use of deoxycholic acid to enhance the oral bioavailability of biodegradable nanoparticles," Biomaterials, vol. 29, no. 6, pp. 703-708, 2008.

[29] N. J. Kavimandan, E. Losi, and N. A. Peppas, "Novel delivery system based on complexation hydrogels as delivery vehicles for insulin-transferrin conjugates," Biomaterials, vol. 27, no. 20, pp. 3846-3854, 2006.

[30] Z. S. Haidar, R. C. Hamdy, and M. Tabrizian, "Protein release kinetics for core-shell hybrid nanoparticles based on the layerby-layer assembly of alginate and chitosan on liposomes," Biomaterials, vol. 29, no. 9, pp. 1207-1215, 2008.

[31] F. Tuğcu-Demiröz, F. Acartürk, S. Takka, and O. KonuşBoyunağa, "Evaluation of alginate based mesalazine tablets for intestinal drug delivery," European Journal of Pharmaceutics and Biopharmaceutics, vol. 67, pp. 491-497, 2007.

[32] P. V. Finotelli, D. da Silva, M. Sola-Penna et al., "Microcapsules of alginate/chitosan containing magnetic nanoparticles for controlled release of insulin," Colloids and Surfaces B, vol. 81, no. 1, pp. 206-211, 2010.

[33] M. George and T. E. Abraham, "Polyionic hydrocolloids for the intestinal delivery of protein drugs: alginate and chitosan-a review," Journal of Controlled Release, vol. 114, no. 1, pp. 1-14, 2006.

[34] Y.-H. Lin, H.-F. Liang, C.-K. Chung, M.-C. Chen, and H.W. Sung, "Physically crosslinked alginate/N,O-carboxymethyl chitosan hydrogels with calcium for oral delivery of protein drugs," Biomaterials, vol. 26, no. 14, pp. 2105-2113, 2005.

[35] P. Spitali, P. Rimessi, M. Fabris et al., "Exon skipping-mediated dystrophin reading frame restoration for small mutations," Human Mutation, vol. 30, no. 11, pp. 1527-1534, 2009.

[36] C. A. Sewry, "Immunocytochemical analysis of human muscular dystrophy," Microscopy Research and Technique, vol. 48, no. 3-4, pp. 142-154, 2000.

[37] Y. Takeshima, M. Yagi, H. Wada et al., "Intravenous infusion of an antisense oligonucleotide results in exon skipping in muscle dystrophin mRNA of Duchenne muscular dystrophy," Pediatric Research, vol. 59, no. 5, pp. 690-694, 2006.

[38] H. Heemskerk, C. de Winter, P. van Kuik et al., "Preclinical PK and PD studies on 2'-O-methyl-phosphorothioate RNA antisense oligonucleotides in the $m d x$ mouse model," Molecular Therapy, vol. 18, no. 6, pp. 1210-1217, 2010.

[39] H. A. Heemskerk, C. L. de Winter, S. J. de Kimpe et al., "In vivo comparison of $2^{\prime}$-O-methyl phosphorothioate and morpholino antisense oligonucleotides for Duchenne muscular dystrophy exon skipping," Journal of Gene Medicine, vol. 11, no. 3, pp. 257266, 2009.

[40] T. Yokota, Q.-L. Lu, T. Partridge et al., "Efficacy of systemic morpholino exon-skipping in duchenne dystrophy dogs," Annals of Neurology, vol. 65, no. 6, pp. 667-676, 2009.
[41] H. H. Tønnesen and J. Karlsen, "Alginate in drug delivery systems," Drug Development and Industrial Pharmacy, vol. 28, pp. 621-630, 2002.

[42] R. Pandey and G. K. Khuller, "Chemotherapeutic potential of alginate-chitosan microspheres as anti-tubercular drug carriers," Journal of Antimicrobial Chemotherapy, vol. 53, no. 4, pp. 635-640, 2004.

[43] Z. Ahmad, R. Pandey, S. Sharma, and G. K. Khuller, "Pharmacokinetic and pharmacodynamic behaviour of antitubercular drugs encapsulated in alginate nanoparticles at two doses," International Journal of Antimicrobial Agents, vol. 27, no. 5, pp. 409-416, 2006.

[44] B. Thu, P. Bruheim, T. Espevik, O. Smidsrød, P. Soon-Shiong, and G. Skjåk-Bræk, "Alginate polycation microcapsules: I. Interaction between alginate and polycation," Biomaterials, vol. 17, no. 10, pp. 1031-1040, 1996.

[45] W. R. Gombotz and S. F. Wee, "Protein release from alginate matrices," Advanced Drug Delivery Reviews, vol. 31, no. 3, pp. 267-285, 1998.

[46] M. González Ferreiro, L. G. Tillman, G. Hardee, and R. Bodmeier, "Alginate/poly-L-lysine microparticles for the intestinal delivery of antisense oligonucleotides," Pharmaceutical Research, vol. 19, no. 6, pp. 755-764, 2002.

[47] O. Borges, J. Tavares, A. de Sousa, G. Borchard, H. E. Junginger, and A. Cordeiro-da-Silva, "Evaluation of the immune response following a short oral vaccination schedule with hepatitis B antigen encapsulated into alginate-coated chitosan nanoparticles," European Journal of Pharmaceutical Sciences, vol. 32, no. 4-5, pp. 278-290, 2007.

[48] J.-Y. Tian, X.-Q. Sun, and X.-G. Chen, "Formation and oral administration of alginate microspheres loaded with pDNA coding for lymphocystis disease virus (LCDV) to Japanese flounder," Fish and Shellfish Immunology, vol. 24, no. 5, pp. 592599, 2008.

[49] Y. Zhang, W. Wei, P. Lv, L. Wang, and G. Ma, "Preparation and evaluation of alginate-chitosan microspheres for oral delivery of insulin," European Journal of Pharmaceutics and Biopharmaceutics, vol. 77, no. 1, pp. 11-19, 2011.

[50] H. Laroui, G. Dalmasso, H. T. T. Nguyen, Y. Yan, S. V. Sitaraman, and D. Merlin, "Drug-loaded nanoparticles targeted to the colon with polysaccharide hydrogel reduce colitis in a mouse model," Gastroenterology, vol. 138, no. 3, pp. 843-853, 2010.

[51] A. I. de las Heras, S. Rodríguez Saint-Jean, and S. I. Pérez-Prieto, "Immunogenic and protective effects of an oral DNA vaccine against infectious pancreatic necrosis virus in fish," Fish and Shellfish Immunology, vol. 28, no. 4, pp. 562-570, 2010.

[52] M.-G. Vannucchi, C. Zardo, L. Corsani, and M.-S. FaussonePellegrini, "Interstitial cells of Cajal, enteric neurons, and smooth muscle and myoid cells of the murine gastrointestinal tract express full-length dystrophin," Histochemistry and Cell Biology, vol. 118, no. 6, pp. 449-457, 2002.

[53] A. Ferlini and P. Rimessi, "Exon skipping quantification by realtime PCR," Methods in Molecular Biology, vol. 867, pp. 189-199, 2012. 

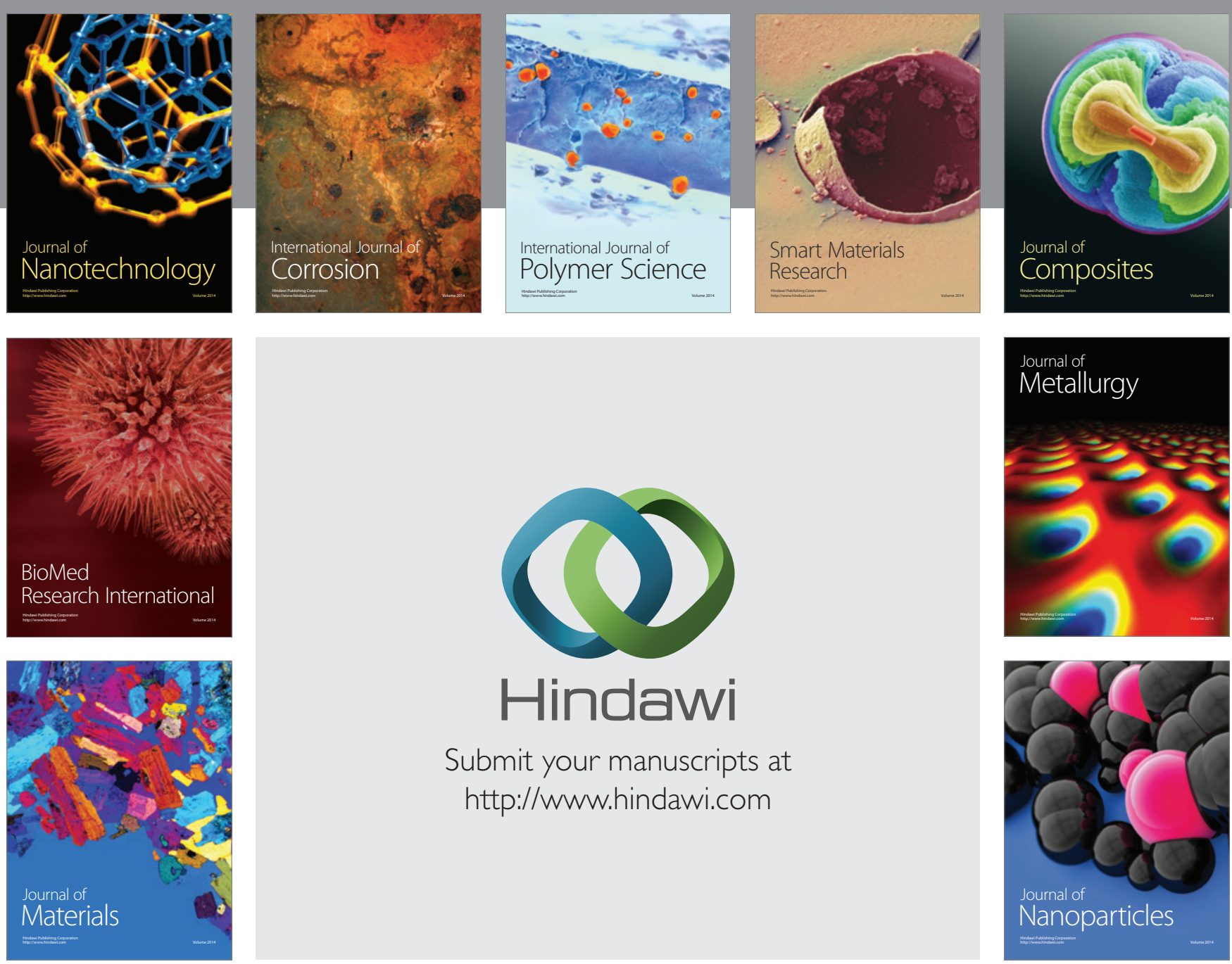

Submit your manuscripts at http://www.hindawi.com
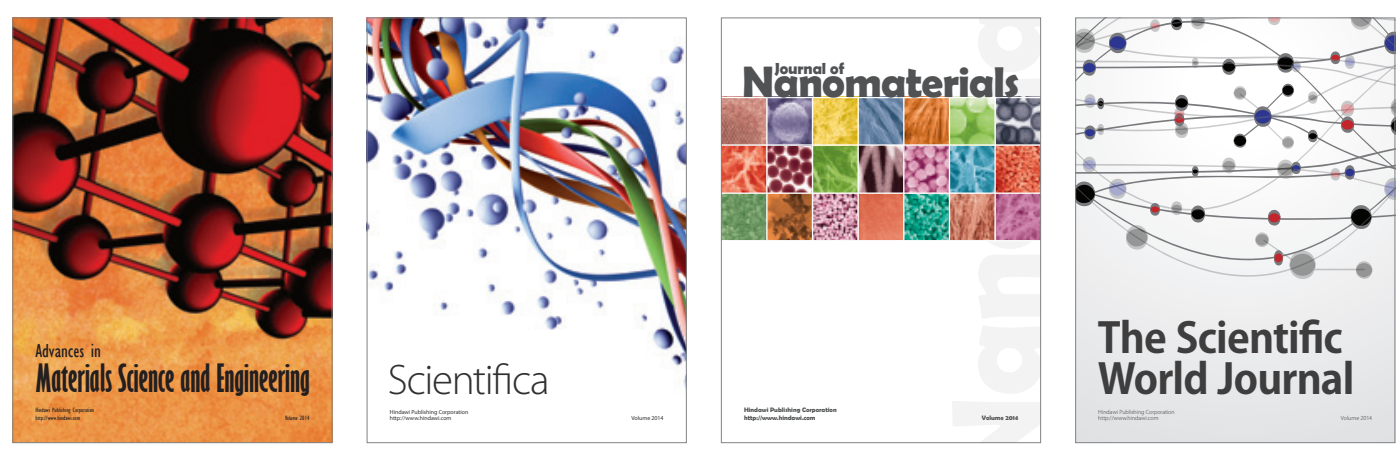

\section{The Scientific World Journal}
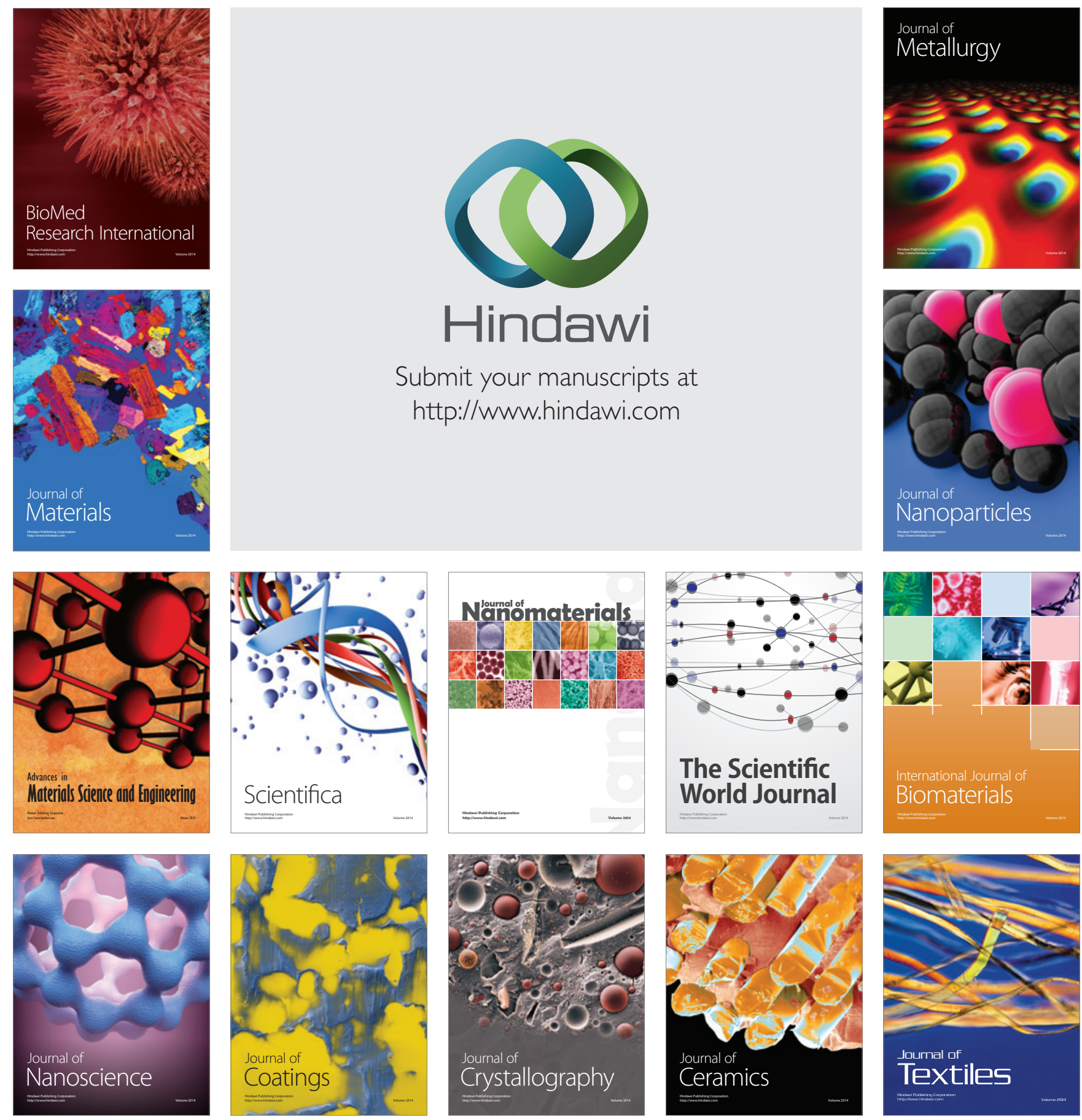